\title{
DISTRIBUIÇÃO DO SISTEMA RADICULAR DO PORTA-ENXERTO COQUINHO SOB COPA DA MANGUEIRA CV. HADEN ${ }^{1}$
}

\author{
ELIOZÉAS VICENTE DE ALMEIDA², FRANCISCO MAXIMINO FERNANDES ${ }^{3}$, \\ APARECIDA CONCEIÇÃO BOLIANI ${ }^{4}$
}

RESUMO - Para o manejo adequado de uma cultura, especialmente frutífera perene, torna-se importante o conhecimento de vários fatores agronômicos, entre os quais o desenvolvimento e a distribuição do sistema radicular. Este trabalho objetivou avaliar a distribuição do sistema radicular do porta-enxerto coquinho sob copa da mangueira cultivar Haden. O estudo foi realizado de março/2005 a maio/2007 em solo argiloso, Latossolo Vermelho distrófico, sob vegetação de cerrado, em pomar implantado em 1992, espaçamento de 10 x 10 m, na Fazenda de Ensino, Pesquisa e Extensão da Faculdade de Engenharia/Unesp/Ilha Solteira, localizada no Município de Selvíria-MS. Os tratamentos utilizados foram: plantas testemunhas, sem aplicação de calcário, e plantas que receberam 3,1 t de calcário ha ${ }^{-1}$. Avaliou-se o sistema radicular, coletando-se amostras de solo e raízes nas profundidades de $0,0-0,20 ; 0,20-0,40 ; 0,40-0,60 ; 0,60-0,80$ e 0,80 a $1,0 \mathrm{~m}$ e nas distâncias do tronco de 0,$83 ; 2,49 ; 4,15 \mathrm{~m}$, classificando as raízes em $<2 ; 2-5 ; 5-10$ e $>10 \mathrm{~mm}$ de diâmetro. As raízes de absorção de maior ocorrência foram as de diâmetro menor do que $2 \mathrm{~mm}$ nos dois tratamentos. A maior concentração de raízes de absorção ocorreu na faixa compreendida entre 0,0 e 1,66 m do tronco e ao longo do perfil analisado, de 0,0 a 1,0 m de profundidade. A maior concentração de raízes de absorção localizou-se até $0,4 \mathrm{~m}$ de profundidade. As plantas que receberam calcário apresentaram aumento de $15,73 \%$ de raízes de absorção em relação à testemunha.

Termos para indexação: Mangifera indica L., distribuição de raízes, calcário.

\section{ROOT SYSTEM DISTRIBUTION OF COQUINHO ROOTSTOCK, ON TOP OF HADEN MANGO CULTIVAR}

\begin{abstract}
For the adequate management of a crop, especially perennial fruit tree, the knowledge of some agronomic factors becomes important, among them the development and the distribution of the root system. The objective of this work was to evaluate the distribution of the root system of the mango Coquinho rootstock, on top of Haden mango cultivar. The study was conducted between March/05 and May/07, in a clay soil, dystrophic Red Latosol (Haplustox), in an orchard implanted in 1992, spacing of 10 x 10 m, at Experimental Station/Unesp/Ilha Solteira, located in Selvíria-MS State. The treatments were: control plants (no lime added) (T1) and plants that received $3.1 \mathrm{t}$ of lime ha ${ }^{-1}$ (T2). The root system, was evaluated through samples collected in the depths of $0.0-0.20 ; 0.20-0.40 ; 0.40-0.60 ; 0.60-0.80$ and 0.80 to $1.0 \mathrm{~m}$ and from the trunk of $0.83 ; 2.49 ; 4.15 \mathrm{~m}$, and the roots were classified into $<2 ; 2-5 ; 5-10 \mathrm{e}>10 \mathrm{~mm}$. The largest occurrence of absorption roots where those with a diameter smaller than $2 \mathrm{~mm}$ in both treatments $\mathrm{T} 1$ and T2. The biggest concentration of absorption roots occurred between zero and $1.66 \mathrm{~m}$ from the trunk and zero and $1.0 \mathrm{~m}$ of depth. The biggest concentration of absorption roots occurred at two first layers of the ground $(0.0-0.40 \mathrm{~m})$. Plants that received lime increased $15.73 \%$ of absorption roots than plants without lime.
\end{abstract}

Index Terms: Mangifera indica L., roots distribution, lime.

\footnotetext{
1'(Trabalho 132-08). Recebido em: 27-05-2008. Aceito para publicação em: 11-05-2009.

${ }^{2}$ Doutor em Agronomia. Empresa Baiana de Desenvolvimento Agricola S/A-EBDA. Av. Dorival Caymmi, 15.649. Itapuã. 41635-150 Salvador-BA. E-mail: eliozeas@zipmail.com.br

${ }^{3}$ Dr. Professor Adjunto Faculdade de Engenharia de Ilha Solteira-Unesp, Dep. Fitos.Eng. Rural e Solos. Av. Brasil. Centro. 15385-000. Ilha Solteira-SP. E-mail: maximino@agr.feis.unesp.br.

${ }^{4} \mathrm{Dr}^{\mathrm{a}}$. Professor Adjunto Faculdade de Engenharia de Ilha Solteira-Unesp, Dep. Fitotecnia,Tec. de alimentos e Sócio Economia. Av. Brasil. Centro. 15385-000. Ilha Solteira-SP. E-mail: boliani@agr.feis.unesp.br.
} 


\section{INTRODUÇÃO}

O Brasil é um grande produtor de frutas, produzindo 39 milhões de toneladas e ocupando o terceiro lugar na produção mundial em 2005 (FAO, 2008). Entre as frutas produzidas encontra-se a manga, ocupando o País atualmente o $8^{\circ}$ lugar na produção e $3^{\circ}$ na exportação mundial dessa fruta (Nehmi et al., 2006).

A mangueira é uma frutífera que se tem destacado no setor agrícola brasileiro. Seu cultivo estende-se por todo o território nacional, com produção em torno de 949 mil toneladas de frutos e ocupando área estimada de 69 mil hectares, no ano de 2004. Bahia, São Paulo e Pernambuco são os maiores produtores, com áreas e produções respectivas de 20,$2 ; 15,4 ; 8,4$ mil ha e 396,$6 ; 204,6$ e 152,7 mil toneladas, cujos valores correspondem em torno de $65 \%$ da área colhida e $75 \%$ da produção brasileira (Harada et al., 2008). No entanto, apesar do potencial brasileiro para produção, têm-se observado alguns entraves para seu cultivo e exportação, principalmente as dificuldades de financiamento, as distâncias entre os locais de produção e o mercado de consumo, bem como as barreiras fitossanitárias impostas pelos importadores.

Segundo Hughes et al. (1992), a raiz é a parte da planta menos conhecida, menos pesquisada e compreendida, principalmente pela razão de não ser vista facilmente. Entretanto, para o manejo adequado de uma cultura, especialmente frutífera perene, torna-se importante o conhecimento de vários fatores agronômicos, entre os quais o desenvolvimento e a distribuição do sistema radicular, visto que práticas como adubação, irrigação, densidade de plantio, manejo do solo e outros tratos culturais poderão ser mais bem equacionados com o conhecimento do sistema radicular da planta, incrementando, dessa forma, a produtividade. Contudo, observam-se poucos trabalhos nessa área, em nível do cerrado brasileiro, referindo-se à cultura da manga.

De acordo com Crestana et al. (1994), o sistema radicular das plantas cultivadas vem assumindo importante papel nos estudos das interações que ocorrem entre o solo, as plantas e outros organismos vivos. Destacam-se, com isso, os aspectos físicos, químicos e biológicos inerentes ao meio e ao solo, favoráveis à distribuição de raízes. Segundo Avilan \& Menezes (1979), os estudos do sistema radicular da mangueira em condições tropicais, em termos gerais, exceto em solos que apresentam limitações ou impedimentos físico-químicos à penetração das raízes, mostram que a maior concentração de raízes ativas situa-se lateralmente a 1,5 $\mathrm{m}$ do tronco, nos solos de textura grossa a média (arenoso e francoarenoso) e nos de textura fina (franco-argiloso) a 2,5 $\mathrm{m}$ alcançando mais de 1,2 metros de profundidade, em plantas com idades de 7; 9 e 17 anos.

O conhecimento da distribuição estática ou dinâmica do sistema radicular de qualquer cultura constitui-se, também, numa relevante ferramenta para a elaboração de um projeto, bem como num elemento essencial para qualquer plano de manejo da irrigação (Coelho et al., 2001).

Choudhury \& Soares (1992) estudaram o comportamento do sistema radicular da mangueira, em solo arenoso sob irrigação por aspersão subcopa, cultivar Tommy Atkins, e observaram que, na distribuição horizontal do sistema radicular, $68 \%$ das raízes de absorção e $86 \%$ das raízes de sustentação estão localizadas na faixa de solo compreendida entre $0,9 \mathrm{e}$ 2,6 m em relação ao caule. Na distribuição vertical do sistema radicular, $65 \%$ das raízes de absorção e 56\% das raízes de sustentação distribuem-se de maneira uniforme nos primeiros $0,60 \mathrm{~m}$ de profundidade.

Portanto, o presente trabalho objetivou avaliar a distribuição do sistema radicular do portaenxerto coquinho sob copa da mangueira cultivar Haden, em solo argiloso sob vegetação de cerrado, em plantas sem aplicação de calcário e em plantas que receberam tratamento com calcário.

\section{MATERIAL E MÉTODOS}

O trabalho foi realizado em um pomar de mangueira cultivar Haden, enxertada sobre portaenxerto cultivar Coquinho, implantado em 1992, no espaçamento de 10 x 10 m, na Fazenda de Ensino, Pesquisa e Extensão da Faculdade de Engenharia/ Unesp, Câmpus de Ilha Solteira, localizada no Município de Selvíria-MS, situada $20^{\circ} 14^{\prime} \mathrm{S}$ e $51^{\circ} 10^{\prime} \mathrm{W}$ com altitude média de $335 \mathrm{~m}$ e clima do tipo Aw, conforme a classificação de Köeppen, com temperatura média anual de $23,7^{\circ} \mathrm{C}$ e precipitação total anual de $1.300 \mathrm{~mm}$.

O solo da área foi classificado como Latossolo Vermelho distrófico, textura argilosa (EMBRAPA, 1999), cuja vegetação natural era cerrado. Retiraramse amostras de solo da camada de 0,0-0,20 m para fins de análise da fertilidade inicial (março/2005), cujos resultados se encontram na Tabela 1.

Em 25 de outubro de 2005, realizou-se a calagem, com distribuição manual do calcário, em área total, incorporando-o na camada de 0-5 $\mathrm{cm}$ de profundidade com o uso de grade leve. $\mathrm{O}$ experimento foi conduzido em blocos casualizados, 2 tratamentos (T1- testemunha, e T2 - que recebeu 
calcário na dose de $3,1 \mathrm{t} \mathrm{ha}^{-1}$, calculada com o objetivo de elevar a saturação por bases a $80 \%$, de acordo com Quaggio et al. (1997)), e duas repetições. As parcelas do experimento foram constituídas por 5 plantas, totalizando 20. O calcário utilizado foi o dolomítico, com as seguintes características: $\mathrm{CaO}$ (39\%); $\mathrm{MgO}$ (13\%); RE (89\%); PN (102\%), PRNT (91\%). Durante os anos agrícolas de 2005/2006 e 2006/2007, efetuou-se adubação de manutenção para o nitrogênio, fósforo e potássio, tomando como base a análise do solo, que indicou as quantidades de $30 \mathrm{~kg}$ de $\mathrm{N}, 40 \mathrm{~kg}$ de $\mathrm{P}_{2} \mathrm{O}_{5}$ e $39 \mathrm{~kg}$ de $\mathrm{K}_{2} \mathrm{O} \mathrm{ha}^{-1}$. Aplicaram-se também $2 \mathrm{~kg} \mathrm{~B}$ ha $^{-1}$ e $1 \mathrm{~kg} \mathrm{Zn} \mathrm{ha-1} \mathrm{(Quaggio} \mathrm{et} \mathrm{al.,}$ 1997). O fósforo (superfosfato simples, $18 \%$ de $\mathrm{P}_{2} \mathrm{O}_{5}$ ), o boro (ácido bórico, $17 \%$ de B) e o zinco (sulfato de zinco, $22 \%$ de $\mathrm{Zn}$ ) foram aplicados em dose única, em dezembro/05 e dezembro/06. O nitrogênio, nos anos de 2005/2006, teve como fonte a ureia $(45 \%$ de N), nos anos de 2006/2007 sulfato de amônio ( $20 \%$ de N) e o potássio teve como fonte cloreto de potássio $(60 \%$ de $\mathrm{KCl}$ ), parcelados em três vezes, sendo a primeira aplicação no início das chuvas (mês de dezembro), a segunda após a colheita (março/abril) e terceira antes do florescimento (maio).

Dezenove meses após a aplicação e incorporação do calcário (maio 2007), realizouse amostragem de solo para avaliar a fertilidade. Foi utilizado um trado tipo caneca na projeção da copa e profundidade de $0,0-0,20 \mathrm{~m}$. Retiraram-se 4 amostras simples da planta do centro da parcela, em 2 repetições. As determinações analíticas foram realizadas de acordo com a metodologia descrita por Raij et al. (2001).

O estudo de raízes foi realizado nas mesmas plantas onde se fez a amostragem de solo. As plantas do tratamento $\mathrm{T} 1$ apresentaram-se com diâmetro médio de copa de 9,50 m e altura média de $8,30 \mathrm{~m}$, e do tratamento 2 (T2), com diâmetro médio de copa de $9,50 \mathrm{~m}$ e altura média de $8,40 \mathrm{~m}$. O método seguido para a avaliação da distribuição do sistema radicular foi uma adaptação do descrito por Ford (1952), citado por Corrêa (1982). Foi utilizado um trado tipo caneca, com $0,10 \mathrm{~m}$ de diâmetro por $0,20 \mathrm{~m}$ de altura, para amostragem de solo e raízes. As amostragens foram realizadas de cada lado do tronco, na direção da linha de plantio, respectivamente, nas distâncias de 0,83 2,49 e 4,15 m, com a finalidade de atingir a máxima distância considerada explorada pelas raízes, $4,98 \mathrm{~m}$ em um total de 5 m (Figura 1), de acordo com Corrêa (1982). Os dados obtidos nos locais de amostragens, dentro das faixas limitadas pelos semicírculos, foram considerados representativos das respectivas áreas.

Em cada ponto de amostragem, foram retiradas amostras de solo e raízes nas profundidades de
0,0-0,2; 0,2-0,4; 0,4-0,6; 0,6-0,8 e 0,8-1,0 m (Figura $1)$, conforme Choudhury \& Soares (1992).

Após a retirada de cada amostra, foi realizado seu peneiramento, ainda no campo, com peneira de malha de $3 \mathrm{~mm}$ de diâmetro, a fim de diminuir o volume de terra e raízes a ser transportado, etiquetando-se cada amostra. Posteriormente, as amostras foram lavadas em peneira de malha de $1,5 \mathrm{~mm}$ de diâmetro, separando-se daí as raízes, que foram armazenadas em sacos de papel, para secagem natural. Em seguida, efetuou-se sua separação, com uso de paquímetro digital, classificando-as em menor que $2 \mathrm{~mm}$; entre 2 e $5 \mathrm{~mm}$; entre 5 e $10 \mathrm{~mm}$ e maior do que $10 \mathrm{~mm}$. Foram consideradas raízes de absorção aquelas que apresentaram diâmetro menor ou igual a $10 \mathrm{~mm}$, e de sustentação, as raízes com diâmetro superior a $10 \mathrm{~mm}$, de acordo com Choudhury \& Soares (1992).

As raízes foram novamente acondicionadas em sacos de papel, perfurados e identificados, secas em estufa à temperatura de $+\mathrm{ou}-65^{\circ} \mathrm{C}$ até o equilíbrio da massa, após 48 horas, sendo pesadas em balança analítica.

Foram coletadas raízes de duas plantas de cada tratamento, T1 e T2, a planta central da parcela de duas repetições diferentes; entretanto, utilizou-se como representativo da amostra a média da matéria seca das raízes, de locais simétricos em relação ao tronco, obtidas das duas plantas.

Através dos resultados das pesagens, foi calculada a massa total da matéria seca das raízes das plantas, considerando-se o diâmetro das distâncias descritas entre cada amostragem e para cada 0,20 $\mathrm{m}$ de profundidade, visto que o volume de cada amostra é conhecido através do volume do trado e da massa das raízes retiradas a cada profundidade, como segue: volume de cada amostra coletada é igual ao volume do trado $\left(\mathrm{V}_{1}\right) ; \mathrm{V}_{1}=\pi \mathrm{D}^{2} . \mathrm{h} / 4$; sendo $\mathrm{V}_{1}=$ $3,1416 \cdot(0,10 \mathrm{~m})^{2} \cdot 0,20 \mathrm{~m} / 4$, onde $\mathrm{V}_{1}=0,0016 \mathrm{~m}^{3}$. O volume da área considerada explorada pelas raízes, com diâmetro constante de $1,66 \mathrm{~m}$ a cada profundidade de $0,20 \mathrm{~m}$ (Figura 1), é representado por $\mathrm{V}_{2} ; \log \mathrm{o}$ $\mathrm{V}_{2}=\pi \mathrm{D}^{2} \cdot \mathrm{h} / 4=3,1416 \cdot(1,66 \mathrm{~m})^{2} \cdot 0,20 \mathrm{~m} / 4$ $=0,4328 \mathrm{~m}^{3}$. Portanto, se para cada volume de $0,0016 \mathrm{~m}^{3}$ corresponde uma massa seca de raízes $X$ (massa encontrada em cada amostra), para cada volume de $0,4328 \mathrm{~m}^{3}$ corresponderá um valor Y, para cada distância correspondente do tronco (valor representativo para o diâmetro de 1,66 m de distância x $0,20 \mathrm{~m}$ de profundidade). 


\section{RESULTADOS E DISCUSSÃO}

Comparando-se os resultados da análise química de solo inicial com os resultados encontrados na análise química das amostras coletadas no período da amostragem de raízes, em maio de 2007 (Tabela 1), observa-se na testemunha que houve alterações para soma de bases (SB), capacidade de troca catiônica (CTC) e saturação por bases $(\mathrm{V} \%)$. Considerando-se que o cálcio é determinado por meio da análise química, a SB, CTC e o $\mathrm{V}(\%)$ são calculados, o aumento desses três últimos provavelmente é devido à elevação do cálcio proveniente da aplicação do adubo superfosfato simples, que contém de 25 a $28 \%$ desse nutriente na sua formulação (Malavolta, 1979). No tratamento T2 (aplicação de 3,1 t ha $a^{-1}$ de calcário dolomítico, dose recomendada para elevar o $\mathrm{V}(\%)$ a 80$)$, verifica-se o efeito benéfico da calagem, porém não atingindo o valor da saturação por base esperado até a época da amostragem (19 meses após sua aplicação).

Nas Tabelas 2 e 3, estão apresentados os resultados da distribuição das raízes, média de duas plantas, correspondentes, respectivamente, à testemunha e ao tratamento que recebeu calcário, para as profundidades de $0,0-1,0 \mathrm{~m}$ e as distâncias compreendidas entre $0,0-1,66 \mathrm{~m} ; 1,66-3,32 \mathrm{~m}$ e 3,32-4,98m do tronco. Pelos resultados, observa-se que as raízes consideradas de absorção, entre 0-10 mm de diâmetro, estão distribuídas no perfil do solo, na profundidade de zero a $1,0 \mathrm{~m}$ nos percentuais correlacionados ao total delas, de 60,$55 ; 24,30$; $15,15 \%$ e 54,$71 ; 26,50 ; 18,79 \%$ nas distâncias do tronco de $0,0-1,66 \mathrm{~m} ; 1,66-3,32 \mathrm{~m}$ e entre 3,32-4,98 m, para a testemunha e o tratamento que recebeu calcário, respectivamente, representado na Figura 2 (a). Avilan \& Menezes (1979) observaram que a maior concentração de raízes ativas está localizada lateralmente, a 1,5 m do tronco nos solos de textura grossa a média.

As raízes de absorção de maior ocorrência foram as de diâmetro menor do que $2 \mathrm{~mm}$, distribuídas ao longo do perfil do solo (camada de $0,0-1,0 \mathrm{~m})$, perfazendo os totais de 49,81 e $49,08 \%$ do total de raízes de absorção, distribuídas entre 27,$36 ; 14,72 ; 7,73 \%$ e 24,$96 ; 13,44 ; 10,68 \%$ nas três distâncias estudadas, para a testemunha e para o tratamento 2, respectivamente (Figura $2 \mathrm{~b}$ ). Estes resultados estão de acordo com aqueles observados por Choudhury \& Soares (1992). Verificou-se também que a ocorrência de raízes de absorção diminuiu à medida que se distancia do tronco da planta, especialmente raízes menores que $2 \mathrm{~mm}$ na camada de $0-0,2 \mathrm{~m}$.

Analisando-se os resultados encontrados, nota-se que 40,71 e $37,46 \%$ das raízes de absorção se encontram na camada de $0,0-0,2 \mathrm{~m}$, destes 62,62 ; 26,$92 ; 10,46 ; 59,05 ; 26,06 ; 14,89 \%$ nas distâncias do tronco de $0,0-1,66 \mathrm{~m} ; 1,66-3,32 \mathrm{~m}$ e $3,32-4,98 \mathrm{~m}$, em plantas dos tratamentos $\mathrm{T} 1 \mathrm{e} \mathrm{T} 2$, respectivamente (Figura $2 \mathrm{c}$ ). Na camada entre 0,2 a $0,4 \mathrm{~m}$, os valores são de 17,19 e $14,81 \%$, destes 52,$30 ; 25,89 ; 21,81$ e 61,$31 ; 19,51 ; 19,18 \%$ nas mesmas distâncias e mesmos tratamentos (Figura 2 d). Portanto, 57,90\% e $52,27 \%$ das raízes de absorção das mangueiras estudadas, nos tratamentos T1 e T2, concentram-se nos primeiros $0,40 \mathrm{~m}$ de profundidade do solo. Esses resultados indicam que, para adubação da mangueira, em pomares com condições semelhantes, essa deverá ser concentrada na faixa compreendida entre zero e 1,66 m do tronco, onde os estudos demonstraram maior desenvolvimento do sistema radicular ativo para a absorção.

As raízes de sustentação na testemunha estão distribuídas nas duas primeiras distâncias do tronco, em percentuais relacionados com o total dessas raízes, sendo $9,08 \%$ entre $0-1,66 \mathrm{~m}$ e $90,92 \%$ entre 1,66-3,32 m. Nas plantas do tratamento 2, estão distribuídas nas três distâncias observadas do tronco, em percentuais de 22,94; 56,49 e $20,57 \%$, respectivamente. Choudhury \& Soares (1992) não observaram raízes de sustentação em mangueiras a partir da distância de 2,60 m do caule.

Comparando-se os valores de massa seca de raízes de absorção (Tabelas 2 e 3), observa-se que o tratamento 2 apresentou aumento de $15,73 \%$ em relação à testemunha, em percentuais relacionados com o total dessas raízes. Por outro lado, comparandose o total geral de massa seca de raízes entre os dois tratamentos, nota-se que o tratamento 2 apresentou aumento de $15,37 \%$. De acordo com Natale et al. (1996), a calagem propicia ambiente favorável ao desenvolvimento do sistema radicular das plantas, visto que promove a elevação do $\mathrm{pH}$, a neutralização do alumínio, além de fornecer cálcio e magnésio. 


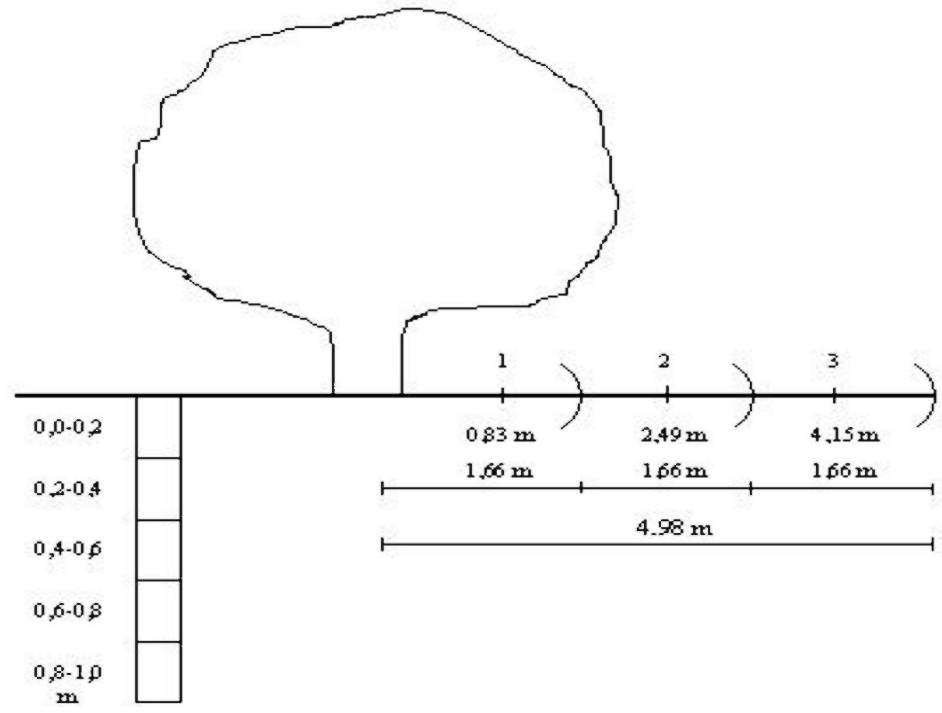

FIGURA 1 - Disposição do local e profundidades de amostragens na área do terreno ocupada pelo porta-enxerto Coquinho sob copa da mangueira cv. Haden, espaçamento 10 x $10 \mathrm{~m}$. Selvíria-MS, 2007.

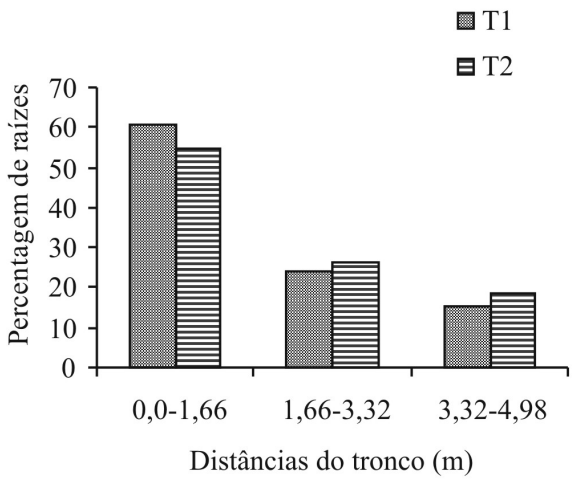

$\mathrm{a}$

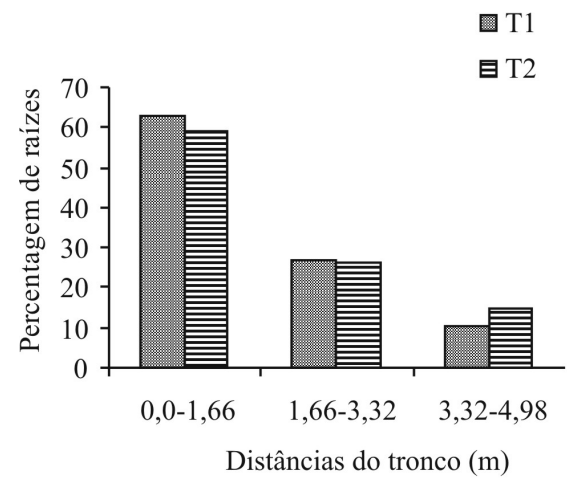

$\mathrm{C}$

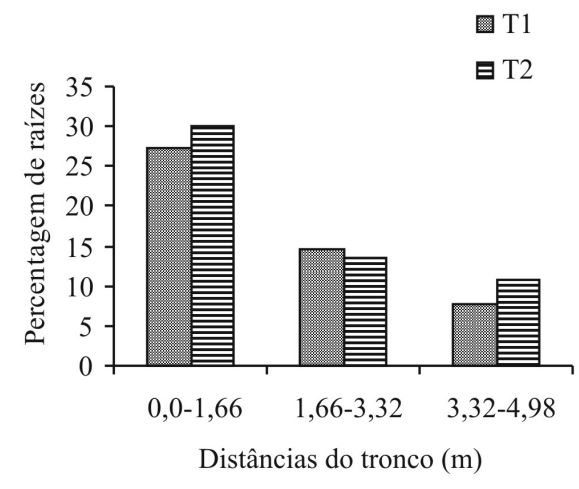

b

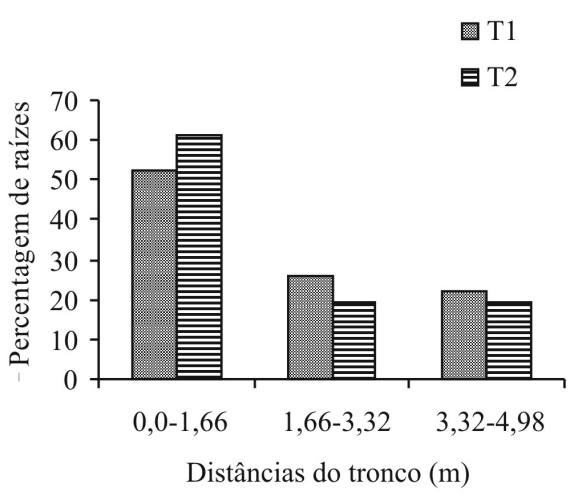

d

FIGURA 2 - Percentuais de raízes de absorção distribuídas nas respectivas camadas e distâncias do tronco: 0 a $10 \mathrm{~mm}$, camada $0-1,0 \mathrm{~m}$ (a), <2 mm, camada $0-1,0 \mathrm{~m}$ (b), 0 a $10 \mathrm{~mm}$, camada de 0-0,2 $\mathrm{m}$ (c), 0 a $10 \mathrm{~mm}$, camada 0,2-0,4 m (d). T1(testemunha - sem calagem) T2 (com calagem). Selvíria-MS, 2007. 
TABELA 1 - Resultados das análises químicas do solo da área do experimento (inicial março/2005 e final maio/2007, 19 meses após a calagem no T2). Selvíria-MS, 2007.

\begin{tabular}{|c|c|c|c|c|c|c|c|c|c|c|c|c|c|}
\hline $\begin{array}{l}\text { Local de } \\
\text { amostragem }\end{array}$ & Data & Trat. & $\begin{array}{c}\mathrm{pH} \\
\mathrm{CaCl} \\
\end{array}$ & M.O. & $\begin{array}{c}\mathrm{P} \\
\text { (Resina) }\end{array}$ & K & $\mathrm{Ca}$ & $\mathrm{Mg}$ & $(\mathrm{H}+\mathrm{Al})$ & $\mathrm{Al}$ & SB & CTC & V \\
\hline & & & & $\mathrm{g} \mathrm{dm}^{-3}$ & $\mathrm{mg} \mathrm{dm}^{-3}$ & & & & mmolc di & $n^{-3}-$ & & & $\%$ \\
\hline Projeção da & 2005 & - & 4,7 & 26 & 9 & 0,9 & 16 & 11 & 42 & 4 & 27,9 & 69,9 & 40 \\
\hline Projeção da & 2007 & $\mathrm{~T} 1$ & 4,7 & 34 & 13 & 0,8 & 27 & 13 & 40 & 3 & 39,8 & 79,8 & 50 \\
\hline copa & 007 & T2 & 5,1 & 36 & 22 & 0,7 & 43 & 22 & 33 & 1 & 65,7 & 98,7 & 67 \\
\hline
\end{tabular}

$\mathrm{T} 1$ - testemunha sem calagem; T2 - com calagem.

TABELA 2 - Massa de matéria seca de raízes do porta-enxerto Coquinho sob copa da mangueira cv. Haden para o Tratamento T1 (sem calagem) considerando as distâncias do tronco e as profundidades de amostragem. Selvíria-MS, 2007.

\begin{tabular}{|c|c|c|c|c|c|c|}
\hline \multirow{3}{*}{$\begin{array}{l}\text { Distância } \\
\text { do tronco } \\
\text { (m) }\end{array}$} & \multirow{3}{*}{ Profundidade (m) } & \multicolumn{5}{|c|}{ Massa das raízes (g) } \\
\hline & & \multicolumn{5}{|c|}{ Diâmetro de raízes } \\
\hline & & $<2 \mathrm{~mm}$ & $2-5 \mathrm{~mm}$ & $5-10 \mathrm{~mm}$ & $>10 \mathrm{~mm}$ & Total \\
\hline $0,0-1,66$ & $\begin{array}{l}0,0-0,2 \\
0,2-0,4 \\
0,4-0,6 \\
0,6-0,8 \\
0,8-1,0 \\
\end{array}$ & $\begin{array}{r}655 \\
230 \\
200 \\
111 \\
68 \\
\end{array}$ & $\begin{array}{r}65 \\
103 \\
289 \\
157\end{array}$ & $\begin{array}{r}476 \\
89 \\
127 \\
271^{-} \\
\end{array}$ & $108^{-}$ & $\begin{array}{r}1196 \\
422 \\
724 \\
268 \\
399 \\
\end{array}$ \\
\hline Total & & 1.264 & 614 & 963 & 108 & 2.949 \\
\hline $1,66-3,32$ & $\begin{array}{l}0,0-0,2 \\
0,2-0,4 \\
0,4-0,6 \\
0,6-0,8 \\
0,8-1,0 \\
\end{array}$ & $\begin{array}{r}414 \\
81 \\
114 \\
57 \\
14 \\
\end{array}$ & $\begin{array}{r}100 \\
33 \\
143 \\
89\end{array}$ & $\begin{array}{r}95^{-} \\
- \\
- \\
\end{array}$ & $\begin{array}{l}411^{-} \\
376 \\
295^{-} \\
\end{array}$ & $\begin{array}{l}514 \\
620 \\
633 \\
146 \\
309 \\
\end{array}$ \\
\hline Total & & 680 & 365 & 95 & 1.082 & 2.222 \\
\hline $3,32-4,98$ & $\begin{array}{l}0,0-0,2 \\
0,2-0,4 \\
0,4-0,6 \\
0,6-0,8 \\
0,8-1,0 \\
\end{array}$ & $\begin{array}{r}162 \\
46 \\
43 \\
84 \\
22\end{array}$ & $\begin{array}{r}38 \\
130 \\
62 \\
124\end{array}$ & $\begin{array}{l}- \\
- \\
- \\
-\end{array}$ & $\begin{array}{l}- \\
- \\
- \\
- \\
-\end{array}$ & $\begin{array}{r}200 \\
176 \\
105 \\
208 \\
22 \\
\end{array}$ \\
\hline Total & & 357 & 354 & - & - & 711 \\
\hline Total Geral & & 2.301 & 1.333 & 1.058 & 1.190 & 5.882 \\
\hline
\end{tabular}

TABELA 3 - Massa de matéria seca de raízes do porta-enxerto Coquinho sob copa da mangueira cv. Haden para o Tratamento T2 (com calagem) considerando as distâncias do tronco e as profundidades de amostragem. Selvíria-MS, 2007.

\begin{tabular}{|c|c|c|c|c|c|c|}
\hline \multirow{3}{*}{$\begin{array}{l}\text { Distância do } \\
\text { tronco }(\mathrm{m})\end{array}$} & \multirow{3}{*}{ Profundidade (m) } & \multicolumn{5}{|c|}{ Massa das raízes (g) } \\
\hline & & \multicolumn{5}{|c|}{ Diâmetro de raízes } \\
\hline & & $<2 \mathrm{~mm}$ & $2-5 \mathrm{~mm}$ & $5-10 \mathrm{~mm}$ & $>10 \mathrm{~mm}$ & Total \\
\hline $0,0-1,66$ & $\begin{array}{l}0,0-0,2 \\
0,2-0,4 \\
0,4-0,6 \\
0,6-0,8 \\
0,8-1,0 \\
\end{array}$ & $\begin{array}{c}741 \\
257 \\
170 \\
122 \\
65 \\
\end{array}$ & $\begin{array}{l}103 \\
130 \\
327 \\
046 \\
016 \\
\end{array}$ & $\begin{array}{c}357 \\
106 \\
233 \\
298 \\
- \\
\end{array}$ & $\begin{array}{l}- \\
\overline{1} 11\end{array}$ & $\begin{array}{c}1.201 \\
493 \\
1.041 \\
466 \\
81 \\
\end{array}$ \\
\hline Total & & 1.335 & 622 & 994 & 311 & 3.282 \\
\hline $1,66-3,32$ & $\begin{array}{l}0,0-0,2 \\
0,2-0,4 \\
0,4-0,6 \\
0,6-0,8 \\
0,8-1,0 \\
\end{array}$ & $\begin{array}{c}438 \\
87 \\
100 \\
62 \\
43 \\
\end{array}$ & $\begin{array}{c}92 \\
70 \\
100 \\
138 \\
30 \\
\end{array}$ & $\begin{array}{c}- \\
2 \overline{7} 9 \\
- \\
-\end{array}$ & $\begin{array}{c}7 \overline{66} \\
- \\
- \\
-\end{array}$ & $\begin{array}{l}530 \\
923 \\
479 \\
200 \\
73 \\
\end{array}$ \\
\hline Total & & 730 & 430 & 279 & 766 & 2.205 \\
\hline $3,32-4,98$ & $\begin{array}{l}0,0-0,2 \\
0,2-0,4 \\
0,4-0,6 \\
0,6-0,8 \\
0,8-1,0 \\
\end{array}$ & $\begin{array}{c}252 \\
100 \\
57 \\
57 \\
114\end{array}$ & $\begin{array}{c}51 \\
54 \\
73 \\
135 \\
- \\
\end{array}$ & $\begin{array}{c} \\
\overline{1} \\
- \\
- \\
\end{array}$ & $\begin{array}{c}- \\
2 \overline{7} 9 \\
- \\
-\end{array}$ & $\begin{array}{l}303 \\
154 \\
536 \\
192 \\
114 \\
\end{array}$ \\
\hline Total & & 580 & 313 & 127 & 279 & 1.299 \\
\hline Total Geral & & 2.665 & 1.365 & 1.400 & 1.356 & 6.786 \\
\hline
\end{tabular}




\section{CONCLUSÃO}

A maior concentração de raízes de absorção ( $<10 \mathrm{~mm}$ de diâmetro) ocorreu na faixa compreendida entre 0,0 e $1,66 \mathrm{~m}$ do tronco distribuídas ao longo do perfil analisado ( 0,0 a $1,0 \mathrm{~m}$ de profundidade). As raízes de absorção de maior ocorrência foram as de diâmetro menor do que $2 \mathrm{~mm}$. A maior concentração de raízes de absorção localizou-se até $0,4 \mathrm{~m}$ de profundidade. A calagem proporcionou aumento de $15,73 \%$ de raízes de absorção em relação à testemunha.

\section{AGRADECIMENTOS}

Os autores agradecem à EBDA-Empresa Baiana de Desenvolvimento Agrícola S/A e UNESP- Faculdade de Engenharia de Ilha Solteira

\section{REFERÊNCIAS}

AGRIANUAL 2006: anuário da agricultura brasileira. São Paulo: FNP, 2006. p.362-369.

AGRIANUAL 2008: anuário da agricultura brasileira. São Paulo: FNP, 2008. p.378-386.

AVILAN, L.R.; MENEZES, L. Efecto de las propiedades físicas del suelo sobre la distribución de las raíces del mango (Mangifera indica L.) Turrialba, Costa Rica, v.29, n.2, p. 117-122, 1979.

COELHO, E. F.; OLIVEIRA, F. C.; ARAÚJO, E. C. E.; VASCONCELOS, L. F. L.; LIMA, D. M. Distribuição do sistema radicular da mangueira sob irrigação localizada em solo arenoso de tabuleiros costeiros. Revista Brasileira de Fruticultura, Jaboticabal, v. 23, n.2 p. 250-256, 2001.

CORRÊA, L. S. Distribuição do sistema radicular de cultivares de abacateiro ( Persea spp.) num solo Podzólico Vermelho amarelo. 1982. 45f. Tese (Doutorado em Solos e Nutrição de Plantas) Escola Superior de Agricultura "Luiz de Queiroz", Universidade de São Paulo, Piracicaba, 1982.
CRESTANA, S.; GUIMARÃES, M. F.; JORGE, L. A. C.; RALISCH, R.; TOZZI, C. L.; TORRE, A.; VAZ, C. M. P. Avaliação da distribuição de raízes no solo auxiliada por processamento de imagens digitais. Revista Brasileira de Ciência do Solo, Viçosa, v.18, n. 3, p.365-371, 1994.

CHOUDHURY, E. N.; SOARES, J. M. Comportamento do sistema radicular das fruteiras irrigadas. I. mangueira em solo arenoso sob irrigação por aspersão sob copa. Revista Brasileira de Fruticultura, Jaboticabal, v. 14, n.3, p. 169-176, 1992.

EMBRAPA. Sistema brasileiro de classificação de solos. Brasília: Centro Nacional de Pesquisa de Solo, Produção de Informações, 1999. 412p.

FAO- FOOD AND AGRICULTURAL ORGANIZATION OF THE UNITED NATIONS. Agricultural production. Disponível em: <http://www.fao.org./ faostat>. Acesso em: 20 jan. 2008.

HUGHES, K. A.; HORNE, D. J.; ROSS, C. W.; JULIAN, J. F. A 10-year maize/oats rotation under three tillage systems: 2. Plant population, root distribution and forage yields. Soil and Tillage Research, Amsterdam, v.22, n.1, p. 145-157, 1992.

MALAVOLTA, E. ABC da adubação. São Paulo: Ceres, 1979. p.76.

NATALE, W.; COUTINHO, E. L. M.; BOARETTO, A. E.; PEREIRA, F. M. Goiabeira: calagem e adubação. Jaboticabal: Funep, 1996. 22p.

QUAGGIO, J. A.; RAIJ, B. van; PIZA JUNIOR, C.T. Frutíferas. In: RAIJ, B. van; CANTARELLA, H.; QUAGGIO, J. A.; FURLANI, A. M. C. (Ed.) Recomendações de adubação e calagem para o Estado de São Paulo. Campinas: Instituto Agronômico/Fundação IAC, 1997. cap. 17, p.121153.

RAIJ, B. van; ANDRADE, J. C.; CANTARELLA, H.; QUAGGIO, J. A. (Ed.). Análise química para avaliação da fertilidade de solos tropicais. Campinas: Instituto Agronômico, 2001. 285p. 